\title{
A GRANULOMETRIA E A CONCENTRAÇÃO DE NUTRIENTES DO SEDIMENTO AFETAM A DENSIDADE POPULACIONAL DO CARANGUEJO-UÇÁ, UCIDES CORDATUS (LINNAEUS, 1763) (BRACHYURA: OCYPODIDAE) EM ÁREAS DE MANGUEZAL?
}

\author{
Pimenta, C.E.R. ${ }^{1,}$; Mazagão, K.F. ${ }^{1,4}$; Rio, J.P.P. ${ }^{1}$; Santos, L.C.M. ${ }^{2}$; Duarte, L.F.A. ${ }^{3}$ \& Pinheiro, M.A.A. ${ }^{1,4}$
}

${ }^{1}$ Universidade Estadual Paulista (UNESP), Instituto de Biociências (IB), Campus Litoral Paulista (CLP), Laboratório de Biologia da Conservação de Crustáceos (LBC/CRUSTA), São Vicente (SP).

${ }^{2}$ Instituto Federal de Educação, Ciência e Tecnologia de São Paulo (IFSP), Campus Pirituba, São Paulo (SP).

${ }^{3}$ Universidade Federal de São Paulo (UNIFESP), Campus Baixada Santista, Instituto de Saúde e Sociedade (ISS), Santos (SP).

${ }^{4}$ Programa de Pós-Graduação em Biodiversidade de Ambientes Costeiros, Universidade Estadual Paulista (UNESP).

*Autor correspondente: kimberlymf@hotmail.com

O caranguejo Ucides cordatus (Linnaeus, 1763) é semiterrestre, endêmico de manguezais e relevante à bioturbação e ciclagem de nutrientes. No entanto, a influência dos parâmetros edáficos sobre a densidade desta espécie ainda são incipientes, podendo esclarecer seus padrões distribucionais. Este trabalho avalia a densidade de U. cordatus em cinco setores pesqueiros de Cananéia (SP) e sua relação com a composição granulométrica e dos nutrientes do sedimento. Estes setores foram propostos com base na extensão do manguezal e influência antrópica, sendo alguns habitados por comunidades tradicionais e outros com elevado adensamento urbano. Cada setor foi composto por duas áreas de manguezal com distinto nível de inundação pelas marés e registro de: 1) densidade do caranguejo, por contagem das galerias com atividade biogênica em quatro quadrados amostrais $(5 \times 5 \mathrm{~m})$; e 2) sedimento, obtido por amostras compostas tomadas entre os quadrados amostrais (5-25m da margem), para análise granulométrica (07 frações) e de nutrientes (11 elementos). Uma análise de correlação foi efetuada entre a densidade (variável dependente) e as demais independentes (granulométricas e nutrientes), verificando o melhor ajuste pelo coeficiente de correlação linear (Pearson) ou não linear (Spearman). A densidade populacional não diferiu entre os cinco setores $\left(2,2 \pm 1,2\right.$ ind. $\left./ \mathrm{m}^{2} ; \mathrm{F}=1,64 ; \mathrm{p}=0,187\right)$, apresentando, segundo a literatura, média indicativa de manguezais sem impacto antrópico $\left(>1,7 \mathrm{ind} . / \mathrm{m}^{2}\right)$. As frações granulométricas e nutrientes foram melhor expressos pelo modelo curvilíneo $(57,1 \%$ e $70,5 \%$, respectivamente). Não houve associação significativa entre a densidade e as variáveis independentes ( $>>0,05)$, apesar de apresentar, como tendência, um maior adensamento de caranguejos em manguezais mais arenosos (areia grossa, média e fina: $0,17 \leq r \leq 0,39 ; p>0,05)$ e com maiores teores de $M g$ e $M n(0,13 \leq r \leq 0,32 ; p>0,05)$, ocorrendo o inverso naqueles lodosos (areia muito fina, silte e argila: $-0,47 \leq r \leq-0,16 ; p>0,05)$ e com menores teores de $\mathrm{B}, \mathrm{Cu}, \mathrm{Fe}, \mathrm{Zn}$ e $\mathrm{Al}$ $(-0,37 \leq r \leq-0,09 ; p>0,05)$. A ausência de significância entre a densidade e os parâmetros edáficos pode ser decorrente da grande área onde os quadrados foram instalados $\left(>1.000 \mathrm{~m}^{2}\right)$, bem como da reduzida representatividade amostral do sedimento. Os resultados indicam um expressiva variação em microescala, com indicação de um maior número de quadrados amostrais, bem como da coleta de sedimento em seu interior, visando a melhor elucidação deste assunto.

Palavras-chave: ambiente costeiro, parâmetros edáficos, parâmetros distribuicionais, Cananéia- SP. 